\title{
Physician Advice for e-Cigarette Use
}

\author{
Christy Kollath-Cattano, PhD, James F. Thrasher, PhD, Amira Osman, PhD, \\ Jeannette O. Andrews, PhD, RN, and Scott M. Strayer, MD, MPH
}

Purpose: To determine characteristics of smokers discussing e-cigarette use with their physician and receiving recommendations from their physician to use e-cigarettes for smoking cessation.

Methods: US adult smokers who had visited a physician in the previous 12 months $(n=2671)$ were surveyed. Logistic generalized estimating equation models were used to assess the characteristics of smokers who (1) talked to a physician about e-cigarettes, and (2) received physician advice to use e-cigarettes for smoking cessation.

Results: $15 \%(n=406)$ of smokers who visited a physician talked with their physician about e-cigarettes. Among those asked whether their physician recommend e-cigarettes for smoking cessation $(n=257), 61 \%$ responded affirmatively. Current e-cigarette users were more likely to talk to their physicians about e-cigarettes (nondaily users vs never users: OR, 2.70; 95\% CI, 1.79-4.05; daily users vs never users: $0 R, 4.29 ; 95 \% \mathrm{CI}, 2.34-7.84)$ and have their physician recommend e-cigarettes for smoking cessation (daily users vs never users: OR, 9.40; 95\% CI, 2.54-34.71).

Conclusions: The majority of smokers who talk to their physician about e-cigarettes report that they received advice to use e-cigarettes to quit smoking, despite limited evidence for their efficacy. More studies are needed to better understand e-cigarette recommendations in clinical settings. ( $\mathrm{J}$ Am Board Fam Med 2016;29:741-747.)

Keywords: Electronic Cigarettes, Physicians, Smoking, Smoking Cessation, Surveys and Questionnaires, Tobacco Products, Tobacco Use Disorder

Electronic cigarette (e-cigarette) use has increased dramatically in recent years, including among smokers using it to facilitate smoking cessation. ${ }^{1,2}$

This article was externally peer reviewed.

Submitted 7 March 2016; revised 14 July 2016; accepted 19 July 2016.

From the Department of Health and Human Performance, College of Charleston, Charleston, SC (CK-C); the Department of Health Promotion, Education, and Behavior, Arnold School of Public Health, University of South Carolina, Columbia (JFT, AO); the University of South Carolina College of Nursing (JOA); and the Department of Family and Preventive Medicine, University of South Carolina School of Medicine (SMS).

Funding: Funding for data collection and analysis was provided by a grant from the National Cancer Institute at the National Institutes of Health (R01 CA167067). The funders had no role in study design, data collection and analysis, decision to publish, or preparation of the manuscript.

Conflict of interest: none declared.

Disclaimer: The content of this article is solely the responsibility of the authors and does not necessarily represent the official views of the National Institute of Health.

Corresponding author: Scott M. Strayer, MD, MPH, Department of Family and Preventive Medicine, University of South Carolina School of Medicine, 3209 Colonial Dr., Columbia, SC 29203 (E-mail: scott.strayer@uscmed.sc.edu).
However, evidence on the effectiveness of e-cigarettes in smoking cessation is limited. ${ }^{3-5}$ The US Preventive Services Task Force ${ }^{6}$ and other regulatory and medical organizations have not found sufficient evidence to recommend their use for cessation. $^{7-9}$

Most physicians seem to believe that e-cigarettes are less harmful than conventional cigarettes ${ }^{10-12}$ and that e-cigarettes promote smoking cessation, with one-third $(35 \%)$ recommending them to patients who smoke cigarettes. ${ }^{10}$ In the only study on this topic from the patient perspective, $27 \%$ of smokers $(n=250)$ reported ever talking with their physician about e-cigarettes; discussions were most prevalent among current e-cigarette users. ${ }^{13}$ Two thirds of those who spoke with their physician about e-cigarettes $(66 \% ; n=165)$ reported that their physician recommended them; however, this study did not assess other correlates of physician recommendations, or whether physicians recommended e-cigarettes specifically for smoking cessation. ${ }^{13}$ To better characterize physician counseling about e-cigarettes, our study evaluates the charac- 
Figure 1. Study flow chart.

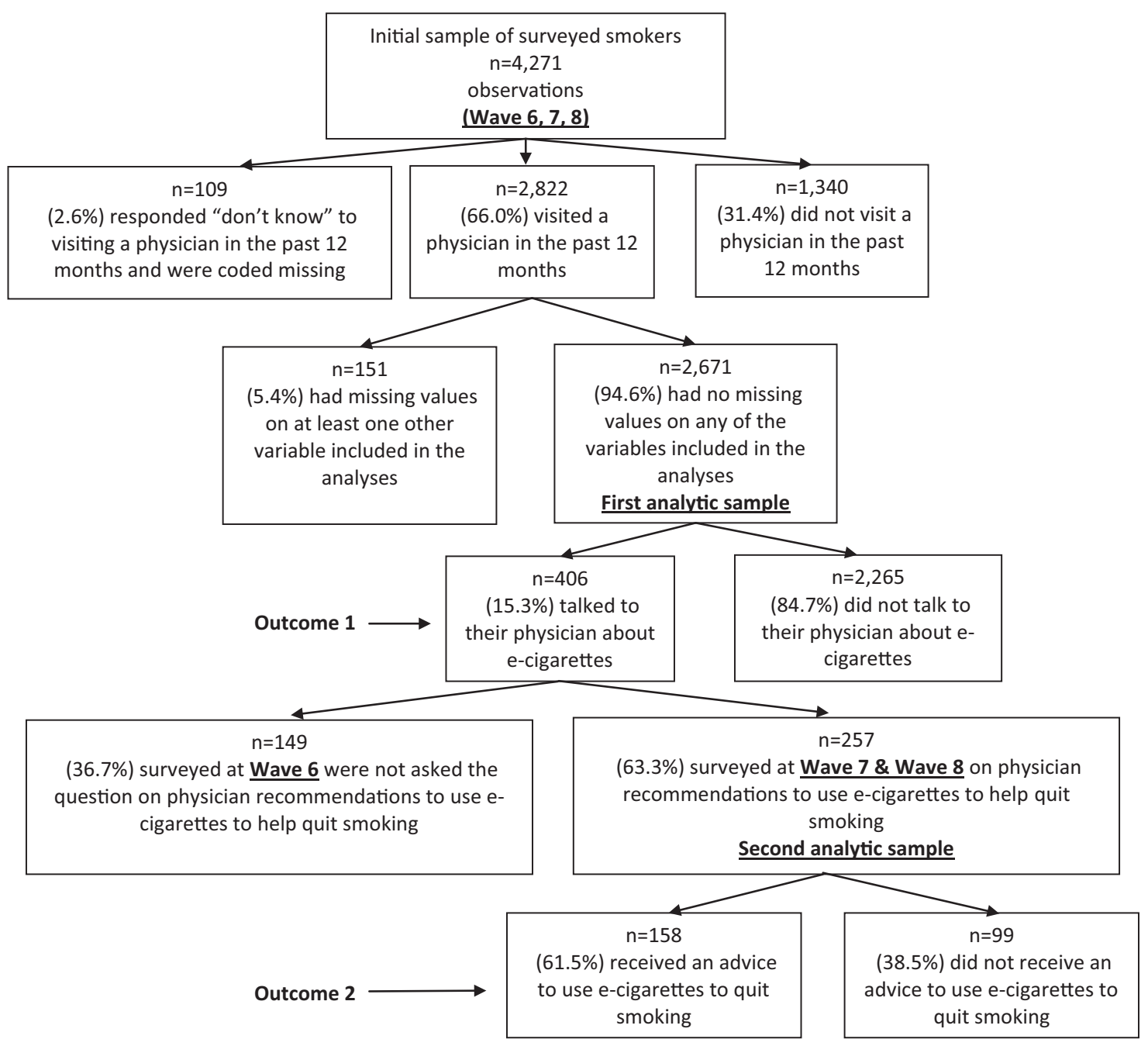

teristics of smokers who report discussing e-cigarettes with their physician and physician recommendations to use e-cigarettes for smoking cessation.

\section{Methods}

\section{Sample}

Data were analyzed from a longitudinal survey of US adult smokers recruited from Global Market Insights (www.gmi-mr.com), which provides online panels of consumers who represent key market segments. Recruitment involved sending invitations to panel participants who were of eligible age and were known smokers, as well as from samples of the general population for which smoking status was unknown. Because of the aims of the parent project, US Latinos were oversampled to allow comparison with a Mexican sample. Eligible partici- pants were smokers aged 18 to 64 years who smoked at least 100 cigarettes in their lifetime and at least once in the previous month.

Data were pooled across waves collected in May 2014 ( $\mathrm{n}=1420$; wave 6), September $2014(\mathrm{n}=$ 1450; wave 7), and January $2015(\mathrm{n}=1401$; wave 8). However, a question about whether smokers received physician advice to quit using e-cigarettes was only asked in waves 7 and 8 (Figure 1). Response rates to invitation E-mails were $16 \%$ at wave $6,4 \%$ at wave 7 , and $3 \%$ at wave 8 . Follow-up rates were $60 \%$ from wave 6 to wave 7 , and $75 \%$ from wave 7 to wave 8. Participants lost to follow-up were replaced to maintain sample sizes at each wave. Participants were compensated from $\$ 1.75$ to $\$ 2.50$ for survey completion. The University of South Carolina's institutional review board approved the study protocol. 


\section{Measures}

Talking to a Physician about e-Cigarettes

At all waves, respondents were asked whether they had visited a physician in the past 12 months. Those who did were asked, "Have you and your doctor talked about e-cigarettes?" $($ no $=0$, yes $=1)$.

\section{Physicians' Advice to Use e-Cigarettes for Smoking Cessation}

In waves 7 and 8, those who reported talking to their physician about e-cigarettes were asked, "Did your doctor recommend that you use e-cigarettes to help you quit smoking regular cigarettes? (no = 0 , yes $=1$ ).

\section{Control Variables}

Standard sociodemographic (age, sex, education, annual household income, race/ethnicity) and smoking-related variables (daily smoking, number of cigarettes smoked per day, intention to quit, and attempts to quit), as well as e-cigarette use, were assessed (Table 1).

\section{Statistical Analyses}

We used 2 analytic samples, which consisted of (1) smokers who visited a physician in the past 12 months, with no missing data on study variables ( $\mathrm{n}=2671$ observations pooled across waves 6,7 , and 8); (2) smokers who talked to their doctor about e-cigarettes and were asked whether they received advice to use them to quit ( $\mathrm{n}=257 \mathrm{ob}-$ servations; $\mathrm{n}=221$ individuals at waves 7 and 8 , when the question on advice was asked) (Figure 1).

Using data from all waves ( $\mathrm{n}=2671$ observations), bivariate and multivariate logistic generalized estimating equation models were estimated, regressing talking to a physician about e-cigarettes on study variables (Table 2). Using data from waves 7 and 8 ( $n=257$ observations), logistic generalized estimating equation models were estimated, regressing receipt of advice to use e-cigarettes to quit on study variables (Table 2). Analyses were weighted for sex, age, and educational profiles of the general population of US smokers based on estimates from the 2012 National Health Interview Survey. ${ }^{14}$ We determined the statistical significance of associations using a Bonferroni-adjusted $\alpha$ level of 0.0042 per test (0.05/12 predictors). All analyses were conducted using Stata software version 13 (StataCorp, College Station, TX).

\section{Results}

Of all participants who visited a physician in the previous 12 months (sample 1), 15\% reported talking to their physician about e-cigarettes, and 61\% of participants asked about doctor recommendations (sample 2) reported that their physician recommended using e-cigarettes to quit regular cigarettes (Table 1). Compared with smokers who never used e-cigarettes, current e-cigarette users were more likely to talk with their physician about e-cigarettes (nondaily users: odds ratio [OR], 2.70; 95\% confidence interval [CI], 1.79-4.05; daily users: OR, 4.29; 95\% CI, 2.34-7.84). Current daily e-cigarette users were also more likely to receive advice to use e-cigarettes for cessation (OR, 9.40; 95\% CI, 2.54-34.71) compared with those who never used e-cigarettes. Smokers who were male or who had recently attempted to quit were more likely than their counterparts to talk to a physician about e-cigarettes (Table 2).

\section{Discussion}

Physician advice on smoking cessation is essential and recommended to decrease smoking, as $>70 \%$ of smokers visit a physician annually. ${ }^{15}$ Recently issued US Preventive Services Task Force recommendations on smoking cessation state that clinicians should use only approved medications and behavioral interventions for smoking cessation (level A recommendation) and cite insufficient evidence for the benefit of e-cigarettes. ${ }^{6} \mathrm{~A}$ recent Cochrane review of e-cigarettes also concluded that the evidence was weak for using these devices for smoking cessation. ${ }^{5}$

Nevertheless, most smokers who spoke with physicians about e-cigarettes reported that their physicians recommended e-cigarettes for smoking cessation $(61 \%)$. The $15 \%$ estimate of the prevalence of e-cigarette discussions is lower than previous estimates $(27 \%)^{13}$; however, this is likely explained by our study asking about the past 12 months, whereas the other study had no time frame. Greater intensity of e-cigarette use was associated with both talking about e-cigarettes and receiving advice to use e-cigarettes for smoking cessation, perhaps indicating that physicians are working with patient preferences and perceive using e-cigarettes as being safer than continuing to 


\begin{tabular}{|c|c|c|}
\hline & $\begin{array}{l}\text { Visited Physician in Past } 12 \text { Months } \\
\qquad(\mathrm{n}=2671)^{*}\end{array}$ & $\begin{array}{l}\text { Talked to Physician About e-Cigarettes } \\
\qquad(\mathrm{n}=257)^{\dagger}\end{array}$ \\
\hline \multicolumn{3}{|l|}{ Age (years) } \\
\hline $18-24$ & 9.8 & 8.9 \\
\hline $25-34$ & 27.3 & 37.0 \\
\hline $35-44$ & 22.1 & 18.3 \\
\hline $45-54$ & 21.6 & 16.0 \\
\hline $55-64$ & 19.2 & 19.8 \\
\hline \multicolumn{3}{|l|}{ Sex } \\
\hline Male & 50.6 & 58.4 \\
\hline Female & 49.4 & 41.6 \\
\hline \multicolumn{3}{|l|}{ Education } \\
\hline High school or less & 20.4 & 14.4 \\
\hline Some college or university & 33.0 & 24.5 \\
\hline Completed college or university & 46.6 & 61.1 \\
\hline \multicolumn{3}{|l|}{ Annual household income } \\
\hline$\leq \$ 29,999$ & 19.9 & 12.8 \\
\hline$\$ 10,000-59,999$ & 31.5 & 24.2 \\
\hline$\geq \$ 60,000$ & 48.6 & 63.0 \\
\hline \multicolumn{3}{|l|}{ Race/ethnicity } \\
\hline White & 56.8 & 59.1 \\
\hline African American & 5.4 & 6.2 \\
\hline Latino & 33.8 & 32.0 \\
\hline Other race & 4.0 & 3.1 \\
\hline \multicolumn{3}{|l|}{ Daily smoking } \\
\hline No & 21.3 & 20.6 \\
\hline Yes & 78.7 & 79.4 \\
\hline Cigarettes per day (n) & $12.0(9.3)$ & $11.8(8.2)$ \\
\hline Heavy Smoking Index (range, 0-6) & $2.3(1.5)$ & $2.4(1.3)$ \\
\hline \multicolumn{3}{|l|}{ Intention to quit in the next 6 months } \\
\hline No & 51.1 & 34.2 \\
\hline Yes & 48.9 & 65.8 \\
\hline \multicolumn{3}{|l|}{ Attempted to quit in the previous 4 months } \\
\hline No & 53.6 & 35.8 \\
\hline Yes & 46.4 & 64.2 \\
\hline \multicolumn{3}{|l|}{ Talked about e-cigarettes } \\
\hline No & 84.8 & \\
\hline Yes & 15.2 & \\
\hline \multicolumn{3}{|l|}{ Received advice to use e-cigarettes to quit } \\
\hline No & & 38.5 \\
\hline Yes & & 61.5 \\
\hline \multicolumn{3}{|l|}{ E-cigarette use } \\
\hline Never used e-cigarettes & 43.1 & 18.7 \\
\hline Tried e-cigarettes/no use in past 4 months & 12.3 & 8.9 \\
\hline Current nondaily use & 38.7 & 58.0 \\
\hline Current daily use & 5.9 & 14.4 \\
\hline
\end{tabular}


Table 2. Results from Adjusted Generalized Estimate Equation Models of Correlates of Talking to a Physician about e-Cigarettes among Those Who Visited a Doctor $(n=2671)$ and Correlates of Receiving Advice to Use e-cigarettes to Quit among Those Who Talked to Their Doctors about e-Cigarettes $(n=257)$

\begin{tabular}{|c|c|c|c|c|c|c|}
\hline \multirow[b]{3}{*}{ Independent Variables } & \multicolumn{6}{|c|}{ Dependent Variables } \\
\hline & \multicolumn{3}{|c|}{ Talked to Physician about e-Cigarettes } & \multicolumn{3}{|c|}{$\begin{array}{c}\text { Received Advice to Use e-Cigarettes to } \\
\text { Quit }\end{array}$} \\
\hline & Respondents (\%) & OR & $95 \% \mathrm{CI}$ & Respondents (\%) & OR & $95 \% \mathrm{CI}$ \\
\hline \multicolumn{7}{|l|}{ Age (years) } \\
\hline $18-24$ & 14 & 1.00 & - & 78 & 1.00 & - \\
\hline $25-34$ & 23 & 1.55 & $0.89-2.67$ & 67 & 0.32 & $0.09-1.16$ \\
\hline $35-44$ & 14 & 1.03 & $0.57-1.86$ & 51 & 0.14 & $0.03-0.65$ \\
\hline $45-54$ & 10 & 1.15 & $0.61-2.17$ & 59 & 0.24 & $0.06-1.06$ \\
\hline $55-64$ & 10 & 1.27 & $0.68-2.38$ & 46 & 0.24 & $0.05-1.13$ \\
\hline \multicolumn{7}{|l|}{ Sex } \\
\hline Male & 18 & 1.00 & - & 67 & 1.00 & - \\
\hline Female & 11 & $0.56^{*}$ & $0.41-0.77$ & 52 & 0.41 & $0.19-0.84$ \\
\hline \multicolumn{7}{|l|}{ Education } \\
\hline High school or less & 13 & 1.00 & - & 60 & 1.00 & - \\
\hline Some college or university & 10 & 0.73 & $0.48-1.09$ & 53 & 0.74 & $0.26-2.06$ \\
\hline Completed college/university & 20 & 0.97 & $0.63-1.47$ & 65 & 0.73 & $0.26-2.05$ \\
\hline \multicolumn{7}{|l|}{ Annual household income } \\
\hline$\geq \$ 29,999$ & 8 & 1.00 & - & 63 & 1.00 & - \\
\hline$\$ 10,000-59,999$ & 13 & 1.19 & $0.68-2.08$ & 44 & 0.55 & $0.17-1.72$ \\
\hline$\geq \$ 60,000$ & 20 & 1.64 & $0.96-2.82$ & 70 & 1.63 & $0.46-5.75$ \\
\hline \multicolumn{7}{|l|}{ Race/ethnicity } \\
\hline White & 12 & 1.00 & - & 61 & 1.00 & - \\
\hline African American & 23 & 1.72 & $0.83-3.57$ & 60 & 1.29 & $0.33-5.07$ \\
\hline Latino & 17 & 1.62 & $1.10-2.38$ & 59 & 1.03 & $0.42-2.49$ \\
\hline Other race & 20 & 1.79 & $0.91-3.52$ & 79 & 2.56 & $0.32-20.08$ \\
\hline \multicolumn{7}{|l|}{ Self-rated health } \\
\hline Poor & 10 & 1.00 & & 90 & 1.00 & - \\
\hline Fair & 11 & 0.97 & $0.37-2.54$ & 55 & 0.08 & $0.006-1.76$ \\
\hline Good & 13 & 1.23 & $0.47-3.17$ & 51 & 0.04 & $0.003-0.56$ \\
\hline Very good & 21 & 1.97 & $0.75-5.16$ & 73 & 0.09 & $0.007-1.36$ \\
\hline \multicolumn{7}{|l|}{ Daily smoking } \\
\hline No & 14 & 1.00 & - & 54 & 1.00 & - \\
\hline Yes & 15 & 0.93 & $0.60-1.42$ & 63 & 1.69 & $0.56-5.10$ \\
\hline Cigarettes per day, mean (SE) & $13.3(0.86)$ & 0.99 & $0.96-1.02$ & $12.9(0.88)$ & 0.99 & $0.93-1.07$ \\
\hline Heavy Smoking Index, mean (SE) & $2.6(0.09)$ & 1.15 & $0.96-1.38$ & $2.5(0.12)$ & 0.87 & $0.54-1.40$ \\
\hline \multicolumn{7}{|l|}{ Intention to quit } \\
\hline No & 9 & 1.00 & - & 63 & 1.00 & - \\
\hline Yes & 21 & 1.26 & $0.83-1.90$ & 60 & 1.03 & $0.45-2.34$ \\
\hline \multicolumn{7}{|l|}{ Attempted to quit } \\
\hline No & 8 & 1.00 & - & 63 & 1.00 & - \\
\hline Yes & 23 & $2.18^{*}$ & $1.45-3.27$ & 59 & 0.52 & $0.21-1.24$ \\
\hline \multicolumn{7}{|l|}{ E-cigarette use } \\
\hline Never used e-cigarettes & 7 & 1.00 & - & 37 & 1.00 & - \\
\hline Tried but no use in past 4 months & 10 & 1.85 & $1.07-3.18$ & 61 & 2.25 & $0.63-8.06$ \\
\hline Current nondaily use & 22 & $2.70^{*}$ & $1.79-4.05$ & 65 & 3.62 & $1.39-9.41$ \\
\hline Current daily use & 34 & $4.29^{*}$ & $2.34-7.84$ & 83 & $9.40^{*}$ & $2.54-34.71$ \\
\hline
\end{tabular}

Data are weighted estimates. Models were adjusted for all variables shown in the table, as well as weights. ${ }^{*} P<.0042$, Bonferroni correction.

$\mathrm{OR}$, odds ratio; CI, confidence interval. 
smoke regular cigarettes. Those who made a recent attempt to quit were also more likely to have talked to their physician about e-cigarettes, suggesting they may have been either considering or already using e-cigarettes for cessation when they spoke with their physician. Women were less likely than men to talk to their physician about e-cigarettes, which may reflect lower e-cigarette use among women. ${ }^{16,17}$ No other sociodemographic variables were associated with study outcomes.

Future research should assess sex differences in how e-cigarettes are addressed during clinical encounters. More research is needed to determine whether these sex differences persist in other samples of smokers. In addition, future studies should explore characteristics of physicians who talk to their patients about e-cigarettes for smoking cessation, the content of these conversations, and subsequent smoking cessation outcomes.

The primary limitation of the study is that the study sample comes from an unknown sampling frame, limiting the generalizability of these results. In addition, our sample replenishment strategy might have introduced some bias; however, we conducted a sensitivity analysis with propensity scores, and the results show no evidence of bias. Moreover, the original and replenishment samples were purposefully assembled to be representative of key marketing segments, even though the patients in the sample had more education than the general population of smokers in the United States. Internet access partly explains this potential sampling bias; as of 2013 , however, $74 \%$ of the US population had household Internet access, thus limiting this bias. ${ }^{18}$ To address this concern, analyses were weighted to resemble the general population of US smokers. Future research should assess whether our results are similar among populations with lower socioeconomic status. The study design limited our ability to determine physician influences; therefore future research should assess smokers' perceptions and use of e-cigarettes before and after discussions with physicians. Smokers' self-reports about clinical encounters may not be accurate, although the direction of biases in our results is unclear. Smokers may have mistakenly believed their physician recommended e-cigarettes for smoking cessation; however, most physicians self-report recommending e-cigarettes for smoking cessation in other research. ${ }^{10}$ In addition, we did not assess who initiated discussions of e-cigarettes or whether physicians recommended evidence-based cessation methods over e-cigarettes. The only study of physician screening for e-cigarettes found that only $24 \%$ of obstetrician-gynecologists reported always asking patients about e-cigarette use. ${ }^{19}$ Research on physician screening and physician-patient dialogue is needed to determine how e-cigarettes are discussed in the context of alternative cessation methods and how patients are advised to use e-cigarettes.

\section{Conclusion}

Despite these limitations, this is the first study to describe discussions of e-cigarettes between physicians and smokers. With the widespread availability, marketing, and use of e-cigarettes, it is increasingly important to understand the role of e-cigarettes in smoking cessation counseling. Our study provides additional evidence that most smokers who speak with their physicians about e-cigarettes receive advice to use them for smoking cessation. These smokers tend to be male and current e-cigarette users. This highlights the need for further research on the efficacy, safety, and use of e-cigarettes among smokers, and on how physicians should talk to their patients about e-cigarettes.

\section{References}

1. Dawkins L, Turner J, Roberts A, Soar K. "Vaping" profiles and preferences: an online survey of electronic cigarette users. Addiction 2013;108:1115-25.

2. Goniewicz MJ, Lingas EO, Hajek P. Patterns of electronic cigarette use and user beliefs about their safety and benefits: an internet survey. Drug Alcohol Rev 2013;32:133-40.

3. Grana R, Benowitz N, Glantz SA. E-cigarettes: a scientific review. Circulation 2014;129:1972-86.

4. Harrell PT, Simmons VN, Correa JB, Padhya TA, Brandon TH. Electronic nicotine delivery systems ("e-cigarettes"): a review of safety and smoking cessation efficacy. Otolaryngol Head Neck Surg 2014; 151:381-93.

5. McRobbie H, Bullen C, Hartmann-Boyce J, Hajek P. Electronic cigarettes for smoking cessation and reduction. Cochrane Database Syst Rev 2014;(12): CD010216.

6. U.S. Preventive Services Task Force (USPSTF). Tobacco smoking cessation in adults, including pregnant women: behavioral and pharmacotherapy interventions. Published final recommendations. September 2015. Available from: http:// www.uspreventiveservicestaskforce.org/Page/ Document/UpdateSummaryFinal/tobacco-usein-adults-and-pregnant-women-counseling-and- 
interventions 1 ?ds $=1 \& \mathrm{~s}=$ Smoking. Accessed September 30, 2016.

7. American Academy of Family Physicians (AAFP). Electronic cigarettes. (C) 2016. Available from: http:// www.aafp.org/about/policies/all/e-cigarettes.html. Accessed September 30, 2016.

8. American Heart Association (AHA). American Heart Association issues e-cigarette recommendations [press release]. August 25, 2014. Available from: http://newsroom.heart.org/news/american-heartassociation-issues-e-cigarette-recommendations. Accessed March 23, 2015.

9. American Medical Association (AMA). AMA supports further regulations of electronic cigarettes to protect youth [press release]. November 10, 2014. Available from: http://www.ama-assn.org/ama/pub/ news/news/2014/2014-11-10-further-regulationelectronic-cigarettes-protect-youth.page. Accessed March 23, 2015.

10. Kandra KL, Ranney LM, Lee JG, Goldstein AO. Physicians' attitudes and use of e-cigarettes as cessation devices, North Carolina, 2013. PLoS One 2014; 29:e103462.

11. Pepper JK, McRee A, Gilkey MB. Healthcare providers' beliefs and attitudes about electronic cigarettes and preventive counseling for adolescent patients. J Adolesc Health 2013;54:678-83.

12. Steinberg MB, Giovenco DP, Delnevo CD. Patientphysician communication regarding electronic cigarettes. Prev Med Rep 2015;2:96-8.

13. Berg C, Haatdoefer R, Escoffery C, Zheng P, Kegler $M$. Cigarette users' interest in using or switching to electronic nicotine delivery systems for smokeless tobacco for harm reduction, cessation, or novelty: a cross-sectional survey of U.S. adults. Nicotine Tob Res 2014;17:245-55.

14. Centers for Disease Control and Prevention. National Health Interview Survey. 2012 data release. Available from: http://www.cdc.gov/nchs/nhis/ nhis 2012 data release.htm. Accessed January 16, 2016.

15. Jamal A, Dube SR, Malarcher AM, Shaw L, Engstrom MC; Centers for Disease Control and Prevention (CDC). Tobacco use screening and counseling during physician office visits among adults-National Ambulatory Med Care Survey and National Health Interview Survey, United States, 2005-2009. MMWR Morb Mortal Wkly Rep 2012;61(Suppl): 38-45.

16. Choi K, Forster J. Characteristics associated with awareness, perceptions, and use of electronic nicotine delivery systems among young US Midwestern adults. Am J Public Health 2013;103:556-61.

17. Etter JF, Bullen C. Electronic cigarette: users profile, utilization, satisfaction, and perceived efficacy. Addiction 2011;106:2017-28.

18. File T, Ryan C; US Census Bureau, US Department of Commerce. Computer and Internet use in the United States: 2013. American Community Survey reports. November 2014. Available from: http:// www.census.gov/history/pdf/2013 computeruse.pdf. Accessed June 1, 2015.

19. England LJ, Anderson BL, Tong VTY, et al. Screening practices and attitudes of obstetricians-gynecologists toward new and emerging tobacco products. Am J Obstet Gynecol 2014;211:695.e1-e7. 